Tyndale Bulletin 70.2 (2019) 269-290

\title{
EPISTOLARY GREETINGS IN THE OXYRHYNCHUS PAPYRI ${ }^{1}$
}

\author{
Peter M. Head \\ (Peter.Head@wycliffe.ox.ac.uk)
}

\begin{abstract}
Summary
This paper examines the function of greetings in letters in the Oxyrhynchus Papyri by focusing on vocabulary, how individuals and groups of people are described, questions relating to format and presentation, differences in format, particularly when greetings are interrupted, and the function of greetings in consolidating and maintaining connections between writers and extended communities. It offers conclusions concerning the placement of greetings, the normal epistolary practice of Graeco-Roman antiquity, and the flexibility in the relationship between the greetings, the situation, and main purpose of the letter. Included is a list of the 74 letters and the text of their greetings.
\end{abstract}

\section{Introduction}

The aim of this paper is to examine the vocabulary, format, role, and function of the greetings contained in the Greek documentary letters from Oxyrhynchus. The investigation arose from an earlier study of epistolary practices in a collection of letters from Claudius Terentianus found in the archive of Claudius Tiberianus. ${ }^{2}$ In that study I noted 'the evident desire expressed by the author for the contact represented by a letter and the news contained in such letters'. ${ }^{3}$ These letters, in common

\footnotetext{
1 An earlier form of this paper was presented to the Papyrology and Early Christian Backgrounds Group at the SBL Annual Meeting in San Antonio (November 2016).

2 P. M. Head, 'The Letters of Claudius Terentianus and the New Testament: Insights and Observations on Epistolary Themes', Tyndale Bulletin 65 (2014): 219-245, esp. pp. 235-39 on the greetings.

3 Head, 'The Letters of Claudius Terentianus and the New Testament', 235-36.
} 
with many other letters from antiquity, contained a variety of references to the desire for correspondence, the joy resulting from receiving a letter, and references to news and gossip passing between the sender and the recipient (and their wider networks). I noted that 'a particular expression of the connections between people is the use of greetings in the closing parts of the letters', including greetings sent to the recipient from those present with the writer and greetings (or instructions to convey greetings) to people at the recipient's location.

These greetings serve to connect, through the vehicle of the written communication, the family group around the sender with the recipient, and the sender with an extensive network of friends and colleagues (some of whom are greeted in other letters as well). ${ }^{4}$

Greetings of various types have, of course, an important place within the letters of the New Testament, and of Paul in particular. The important role of greetings within ancient epistolary practice has been widely recognised and attempts have been made to relate the greetings within the New Testament to ancient epistolary practice. ${ }^{5}$ Two particular advances reflected in this study are to focus on how greetings function within a representative sample of ancient letters and to utilise the opportunity made available by the presence of digital images of many of these papyrus texts online. ${ }^{6}$ The basic corpus for comparison here is the documentary letters written between 200 BC and AD 200 which have been published within The Oxyrhynchus Papyri volumes (1-82) and which contain some form of specific greeting. ${ }^{7}$ To this, I

4 Head, 'The Letters of Claudius Terentianus and the New Testament', 238.

5 H. Koskenniemi, Studien zur Idee und Phraseologie des griechischen Briefes bis 400 n. Chr. (Annales Academiae Scientiarum Fennicae, Ser. B, tom. 102. 2; Helsinki: Suomalainen Tiedeakatemia, 1956): 148-51; F. X. J. Exler, The Form of the Ancient Greek Letter: A Study in Greek Epistolography (Washington DC: Catholic University of America, 1923): 69-77; T. Y. Mullins, 'Greetings as a New Testament Form', JBL 88 (1968), 418-26; J. L. White, 'Epistolary Formulas and Clichés in Greek Papyrus Letters', SBL 1978 Seminar Papers 2 (1978): 289-319, esp. pp. 298-99; J. A. D. Weima, Neglected Endings: The Significance of the Pauline Letter Closing (JSNT SS 101; Sheffield: JSOT Press, 1994): 39-45, 104-17.

6 Cf. recently S. Reece, Paul's Large Letters: Paul's Autographic Subscriptions in the Light of Ancient Epistolary Conventions (LNTS 561; London: Bloomsbury, 2017): ix and throughout on the benefits of relating published editions of papyri to digital images.

7 Greek texts are cited from www.papyri.info (where information on digital images is also found); ETs are generally from the first edition, sometimes adjusted by the author. 
have added documentary letters definitely from Oxyrhynchus and published in other collections. ${ }^{8}$

Of the broader collection of 217 letters, 74 have at least one greeting. This may not mean that all the other letters initially lacked greetings, as many are fragmentary and some are not fully published. ${ }^{9}$ Nevertheless, the initial impression is that under half of all the letters include a greeting section - it is by no means a universal feature of ancient epistolary communication. In what follows we shall begin with observations on the vocabulary used (section 2), then turn to the how individuals and groups of people are described (section 3), some questions of format and presentation (section 4), and then investigate variations to the standard format, especially when greetings are interrupted by other issues of concern to the writer (section 5), before offering some general conclusions (section 6). A list of the 74 letters with the text of their greetings is attached.

\section{Vocabulary and usage}

Three terms are used in epistolary greetings in the Oxyrhynchus Papyri: $\dot{\alpha} \sigma \pi \alpha ́ \zeta o \mu \alpha 1, \pi \rho 0 \sigma \alpha \gamma o \rho \varepsilon v ́ \omega$, and $\dot{\varepsilon} \pi \_\kappa o \pi \varepsilon ́ \omega .{ }^{10}$ The primary term

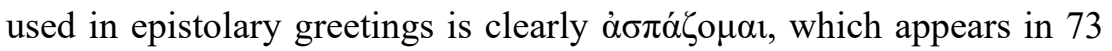
out of the 74 letters with greetings. In 25 of those it is repeated twice, and in 7 letters it is repeated three times (normally when used multiple times at least once in the imperative form and once in the indicative). ${ }^{11}$

8 E.g. many PSI papyri come from later Italian excavations in the same city; P. Oxy.Hels is a collection of Oxyrhynchus papyri donated from the EES collection in Oxford to Helsinki University; other letters of definite Oxyrhynchus provenance are also included.

9 Letters may lack a specific greeting because of the brief specific contents, or because of the type of letter, or because of damage (e.g. P. Oxy 1154, which clearly

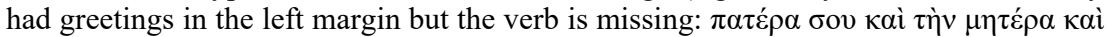
$\tau$ 七ò $\varsigma \dot{\alpha} \delta \varepsilon[\lambda \varphi o v ̀ \varsigma ;$ or P. Oxy 2191, which also clearly had some greeting - based on the presence of $\alpha \delta \pi \alpha \sigma \alpha 1$ - but the rest of the surrounding lines is unreadable). An interesting example is P. Oxy 115 (II), a letter of consolation, which, while lacking greetings, does specifically include other people into the consolation: 'I was as much grieved and shed as many tears over Eumoerus as I shed for Didymas, and I did

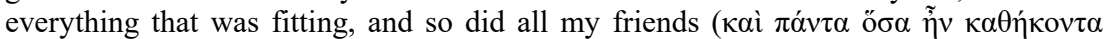

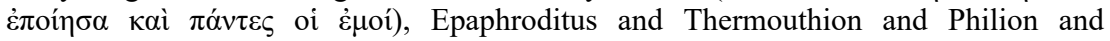
Apollonius and Plantas.'

10 For these three in ancient Greek letters more broadly see H. Koskenniemi, Studien zur Idee und Phraseologie, 149.

$11 \dot{\alpha} \sigma \pi \alpha \dot{\zeta} \zeta \alpha \alpha$ is also the normal verb for greetings in NT letters: $21 \mathrm{x}$ in Rom. 16; 4x in 1 Cor. 16.19ff.; $2 \mathrm{x}$ in 2 Cor .13.12; $3 \mathrm{x}$ in Phil. 4.21f; $4 \mathrm{x}$ in Col. 4.10-15; $1 \mathrm{x}$ in 
The same verb is translated in a variety of ways by the editors of the papyri in The Oxyrhynchus Papyri, including 'salutations', 'salute', 'greet', 'give my regards to', 'send best wishes', 'give best wishes', 'send greetings', 'send regards', 'give greetings', and 'greetings'. ${ }^{12}$

The verb $\alpha \sigma \pi \alpha \zeta^{\prime}{ }_{0} \mu \alpha$ is used in these letters in both the imperative and the indicative. Among the many letters which have both forms, the imperative generally comes first, and then the indicative. The imperative form is used to instruct or request the recipient of the letter to greet people in their location and network of relationships. These are mostly singular imperatives; the aorist form ö $\sigma \pi \alpha \sigma \alpha l$ is used 30 times in these letters, while the present form $\dot{\alpha} \sigma \pi \alpha \dot{\zeta} \zeta o v$ occurs 19 times (there is no obvious distinction between the two, and one letter, P. Oxy 530, uses both forms). The plural form $\dot{\alpha} \sigma \pi \alpha \dot{\sigma} \alpha \sigma \theta \varepsilon$ is used in only one letter (two times in P. Oxy 533), a letter addressed to two recipients. The indicative form is used to report greetings from those present with the writer towards the recipient. The most common is the third-person singular $\dot{\alpha} \sigma \pi \alpha \dot{\zeta} \varepsilon \varepsilon \alpha \hat{i}$, which is found 31 times (sometimes for greetings from more than one person, i.e. not strictly singular); the third-person plural form $\dot{\alpha} \sigma \pi \alpha \dot{\zeta} \sigma o v \tau \alpha$ is found 7 times (each of these does reflect a plurality); the first-person plural form $\dot{\alpha} \sigma \pi \alpha \zeta o$ $\mu \varepsilon \theta \alpha$ is found 2 times; and the first-person singular form $\dot{\alpha} \sigma \pi \alpha ́ \zeta o \mu \alpha$ is found 12 times. $^{13}$ Emphasis is added either by the use of $\pi \mathrm{o} \lambda \lambda \dot{\alpha}$, used adverbially on three occasions (P. Oxy 3062 (I); P. Oxy 114 (II-III); P. Oxy 930 (II/III), or

1 Thess. 5.26; $1 \mathrm{x}$ in Phil. 23; $2 \mathrm{x}$ in 2 Tim. 4.19-21; $2 \mathrm{x}$ in Tit. 3.15 ; $2 \mathrm{x}$ in Heb. 13.24; $2 \mathrm{x}$ in 1 Pet. 5.13f; $1 \mathrm{x}$ in 2 John 13 ; $2 \mathrm{x}$ in 3 John 15 . For the most part, these multiple occurrences include both imperatival and indicative forms.

12 See BDAG 144 for a good discussion of the range of meanings found in early Christian literature (LSJ, 258: 'welcome kindly, greet'). Of its use in written greetings (47 out of 60 total occurrences within the NT) BDAG suggests 'the imperative may be translated greetings to (someone) or remember me to (someone); other moods than imperative may be rendered wish to be remembered, greet, send greetings'. BDAG 144.

13 The first-person greeting can be used both for authorial greetings, especially those that immediately follow the opening of the letter (so, e.g., P. Oxy 2593 (II); P. Oxy

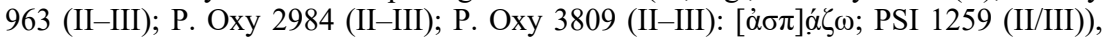
for normal personal greetings (e.g. P. Oxy 1758 (II); P. Oxy 3990 (II); P. Oslo II.52 (II); P. Oxy 1216 (II-III); P. Oxy 1294 (II/III)), and also for secretarial greetings (e.g. P. Oxy 3062; P. Oxy 3057 [following the suggestion of J. Rea reported in the ed. prin. and cf. BL VIII (1992).265]). This latter group has an obvious connection with Rom.

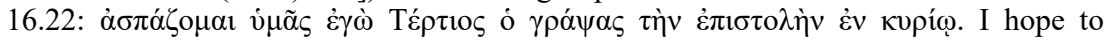
address this in a fuller study. 
$\lambda \varepsilon i \alpha v$, used twice in the same letter (P. Oxy 2593, II), or $\mu \varepsilon \gamma \alpha \dot{\lambda} \omega \varsigma$, used once (P. Wash. Univ. 2:106, 18 BC). ${ }^{14}$

Two other terms are also found within epistolary greetings: $\pi \rho о \sigma \alpha \gamma о \rho \varepsilon v ́ \omega$ and $\dot{\varepsilon} \pi \_\kappa o \pi \varepsilon \dot{\varepsilon} \omega .{ }^{15}$ They are each used in four letters. On

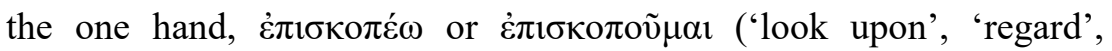
'visit', LSJ) is used in four letters, where it occurs once each time, generally in the imperative (and with no usage of $\dot{\alpha} \sigma \pi \alpha \dot{\zeta} \zeta 0 \mu \alpha$ in these

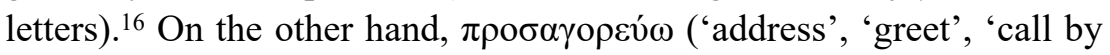
name', LSJ) is used in four letters (P. Oxy 928; 2559; 4959; PSI 1359), three of which also use a form of $\dot{\alpha} \sigma \pi \alpha \dot{\zeta}$ opal. P. Oxy 2559 (II) uses $\dot{\alpha} \sigma \pi \alpha \dot{\zeta} \varepsilon \tau \alpha 1$ for sending greetings from those with the writer ('my wife/partner' and 'the children') and $\pi \rho 0 \sigma \alpha \gamma o ́ \rho \varepsilon v \varepsilon$ for requesting greetings be passed on to those with the recipient (names obscured). PSI 1359 (II-III) has a similar usage, but in the other order, moving from $\pi \rho 0 \sigma \alpha \gamma o ́ \rho \varepsilon v \varepsilon$ used for greeting 'all those who are yours, from me'

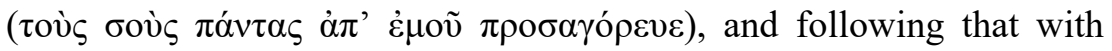
$\dot{\alpha} \sigma \pi \alpha ́ \zeta \varepsilon \tau \alpha \iota$ for greetings from those with the writer ('Cyrilla and her mother and father'). P. Oxy 4959 (II) has the opposite combination:

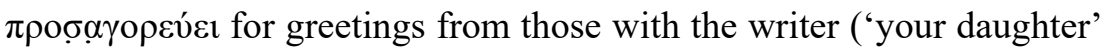
and 'my brother') and $\dot{\alpha} \sigma \pi \alpha \dot{\zeta} \varepsilon \sigma \theta \varepsilon$ for requesting greetings passed on to those with the recipient ('Ptolemaus and Antiochus the brothers').

\section{People and groups of people invoked in greetings}

Most of the greetings, both those from the writer's circle directed towards the recipient and those which the writer directs towards the recipient's circle, concern particular named or identified people. P. Oxy 117 (II-III) offers a straightforward example. This letter is addressed from Chaereas to Dionysius (his brother) and covers a variety of practical matters. It concludes with greetings and a final wish for health:

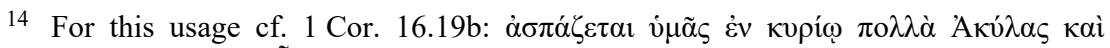

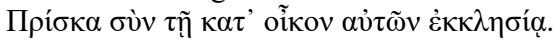

15 Neither is used in similar contexts within the NT letters - for $\pi \rho 0 \sigma \alpha \gamma o \rho \varepsilon v 0 \omega$ in

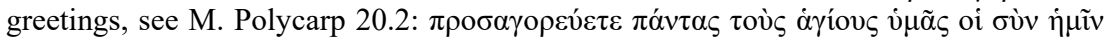

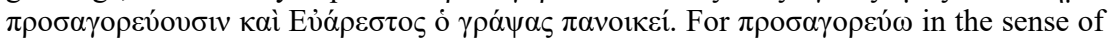

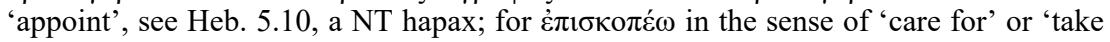
care', see Heb. 12.15; 1 Pet. 5.2 (v.l.).

16 P. Oxy 294 (AD 22); P. Oxy 2838 (AD 62); P. Oxy 3852 (II): all of these have $\dot{\varepsilon} \pi ı \sigma \kappa \pi \mathrm{o}$ (the imperatival form, with some variable spelling). 


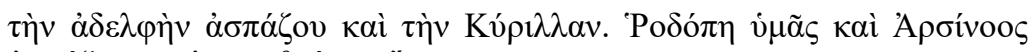

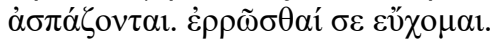

Greet [your] sister and Cyrilla. Rhodope and Arsinous greet you. I pray for your health.

Sometimes they can be more extensive, as for example in the more substantial letter from Dionysius to his mother Tetheus (P. Oxy 530, II), which names more than twelve individuals:

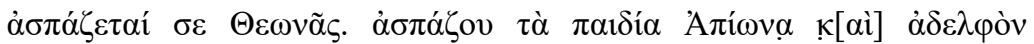

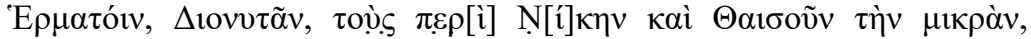

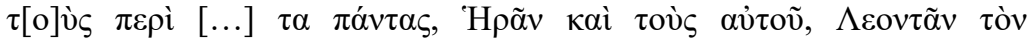

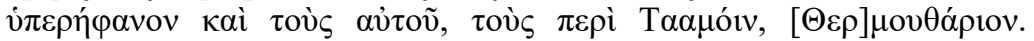

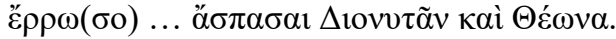

Theonas greets you. Greet the boys Apion and his brother Hermatois, Dionutas, those with Nice and the little Thaisous, all those with ... Heras and those who are with him, Leontas the proud and those who are with him, those with Taamois, and Thermoutharion. Goodbye ... Greet Dionutas and Theon.

As these two examples suggest, within greetings we find names alone, or names with some qualifier ("his brother Hermatois ... the little Thaisous ... Leontas the proud'), or a statement of relationship ('your sister'). The most common are familial terms which naturally encapsulate many of the people writers wished to greet (in order of frequency within our sample we found as follows): ${ }^{17}$

$$
\begin{aligned}
& \pi \alpha 1 \delta i ́ \alpha \text { 'children' - } 15^{18}
\end{aligned}
$$

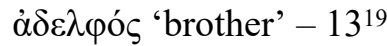

$$
\begin{aligned}
& \mu \eta \dot{\tau} \eta \rho \text { 'mother' }-11^{20} \\
& \pi \alpha \tau \eta \dot{\rho} \text { 'father' - } 10^{21}
\end{aligned}
$$

17 For a helpful discussion and a caution against taking such terms in letters as generally fictive, see E. Dickey, 'Literal and Extended Use of Kinship Terms in Documentary Papyri', Mnemosyne 57 (2004): 131-76.

18 P. Oxy 1061, 22 BC; P. Oxy 5049, AD 59; P. Oxy 5286, AD 82; P. Oxy 3808, I/II; P. Oxy 530, II; P. Oxy 1582, II; P. Oxy 1760, II; P. Oxy 2559, II; P. Oxy 2594, II; P. Oxy 2787, II [bis]; P. Oxy 2981, II [bis]; P. Oxy 928, II/III; P. Oxy 930, II/III.

19 P. Oxy 2148, AD 27 [plural]; P. Oxy 295, AD 35; SB 3.7258, AD 88-96; P. Oxy.Hels 46, I-II; P. Oxy 530, II; P. Oxy 2786, II [plural]; P. Oxy 3990, II; P. Oxy 4959, II [sg. \& pl.]; P. Oslo II.52, II [pl.?]; P. Oxy 2982, II/III [pl.]; P. Oxy 3993, IIIII; P. Oxy.Hels 48, II-III.

20 P. Oxy 3356, AD 76; P. Oxy.Hels 46, I-II; P. Oxy 529, II; P. Oxy 1582, II; P. Oxy 2559, II; P. Oxy 3992, II [bis]; P. Oslo II.52, II; P. Oxy 3991, II-III; PSI 1359, II-III; P. Oxy.Hels 48, II-III. 


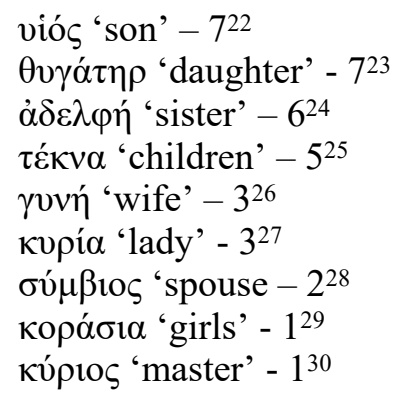

References to 'children' are often accompaned by the adjective $\dot{\alpha} \beta \alpha \sigma \kappa \alpha ́ v \tau o$, implying a wish that they be kept 'secure against enchantments', 'free from harm'. ${ }^{31}$ Occasional other terms are also used. $^{32}$

In addition to such familial terms we can also observe in P. Oxy 530 , in addition to the named individuals, that the writer sends greetings to rather generalised groups of people, using either a) $\tau$ ov̀ $\varsigma$

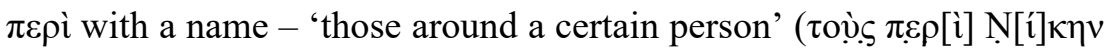

21 P. Oxy 294, AD 22; P. Oxy 295, AD 35; P. Oxy.Hels 46, I-II; P. Oxy 1581, II; P. Oxy 3199, II; P. Oxy 3991, II-III; PSI 1332, II-III; PSI 1359, II-III; P. Oxy.Hels 48, II-III [bis].

22 P. Oxy 2838, AD 62 [bis]; P. Oxy 1581, II; P. Oxy 1582, II; P. Oxy 2679, II; P. Oxy 160, II-III; P. Oxy 533, II/III [pl.]; P. Oxy 3993, II-III.

23 P. Oxy 1584, II [bis]; P. Oxy 3992, II; P. Oxy 4959, II; P. Oxy 533, II/III; P. Oxy 1294, II/III; P. Oxy 3993, II-III.

24 P. Oxy 295, AD 35; P. Oxy.Hels 46, I-II; P. Oxy 2594, II; P. Oxy 117, II-III; P. Oxy 930, II/III [pl.]; P. Oxy.Hels 48, II-III.

25 P. Oxy 2148, AD 27; P. Oxy 529, II; P. Oxy 2860, II; P. Oxy 3312, II; P. Oxy 3313, II.

26 P. Oxy 1479, I BC; P. Oxy 2148, AD 27 [plural]; PSI 1332, II-III.

27 P. Oxy.Hels 46, I-II; P. Oxy 3992, II; PSI 1259, II/III.

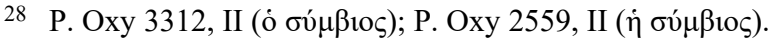

29 P. Oxy 2860, II.

30 P. Oxy $300, \mathrm{I}$.

31 LSJ, 2 (noting the term was used 'esp. of children'); P. Oxy 2594, II: $\tau \grave{\alpha} \alpha$ $\beta \alpha ́ \sigma \kappa \alpha v \tau \alpha ́$

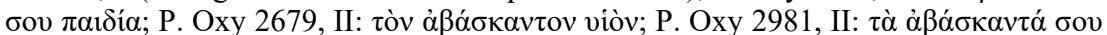

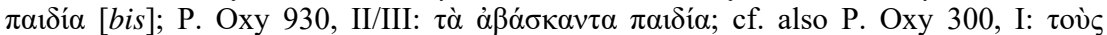

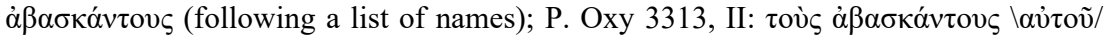
(preceding a list of names).

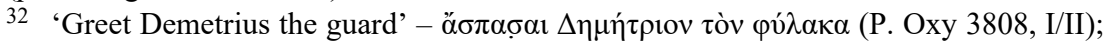

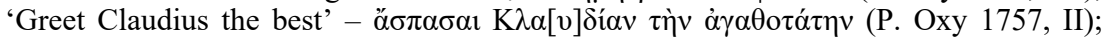

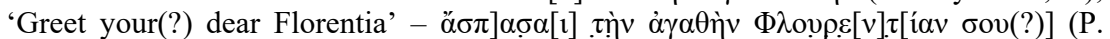

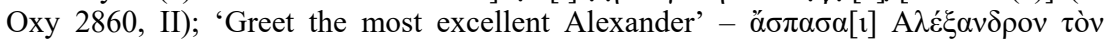

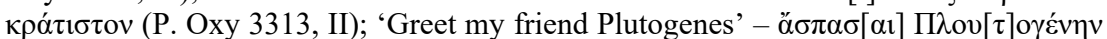

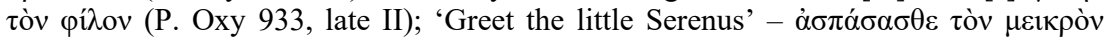

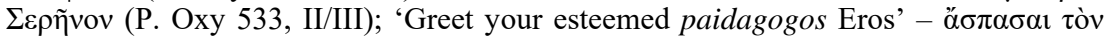
$\tau \varepsilon \iota \iota 1 \omega ́ \tau \alpha \tau o v \pi \alpha \iota \delta \alpha \gamma \omega \gamma o ́ v ~ \sigma o v ~ ” Е \rho \omega \tau \alpha$ (P. Oxy 930, II/III). 


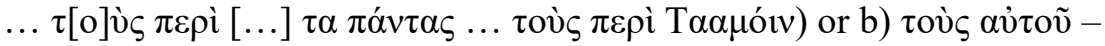

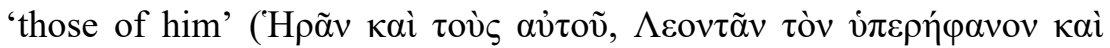

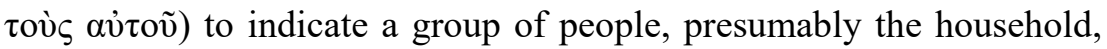
of particular individuals. Throughout the Oxyrhynchus Papyri a variety of different expressions are used to indicate that greetings either come from, or are directed to, a wider group of people (who are not named), often using some form of 'all' to generalise (as P. Oxy 530 does as well, although the name is missing due to damage: $\tau[0] \dot{\varsigma} \varsigma \pi \varepsilon \rho \grave{~}[\ldots] \tau \alpha$ $\pi \alpha ́ v \tau \alpha \varsigma)$.

For greetings from those with the writer we find the simple

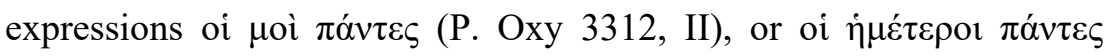
(P. Oxy 930, II/III). For greetings directed to those with the recipient

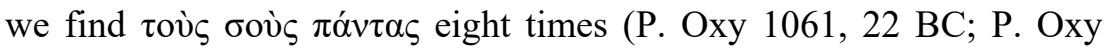
298, I; P. Oxy 4624, I; P. Oxy 3057, I/II; P. Oxy 1584, II; P. Oxy 2680, II; P. Oxy 2984, II-III; PSI 1359, II-III), or, with different word order,

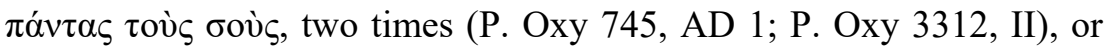

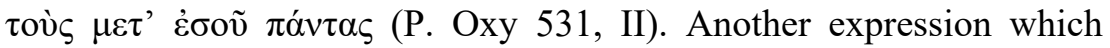
suggests solidarity between the writer and the recipient is $\tau$ ov̀ $\pi \alpha \rho$ '

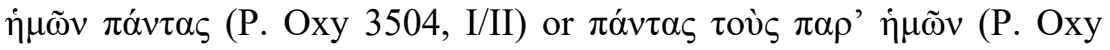

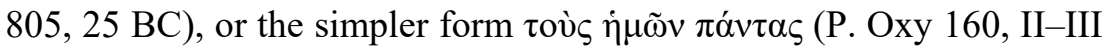
[bis]; P. Oxy 533, II/III; PSI 1259, II/III). Another way to express this is to use either a verb or noun indicating friendly relations: $\tau$ ov̀

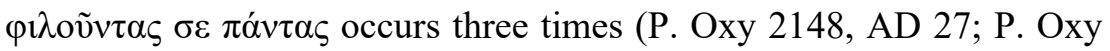

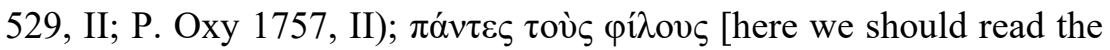

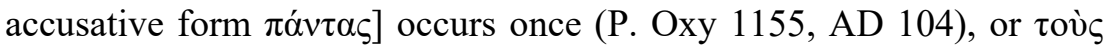

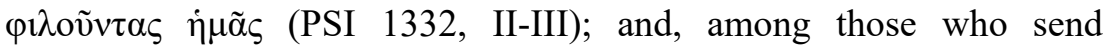

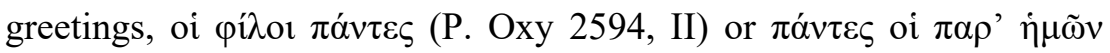
(P. Oxy 298, I), or oi $\dot{\eta} \mu \tilde{\omega} v \pi \alpha ́ v \tau \varepsilon \varsigma$ (PSI 1259, II/III). Sometimes the

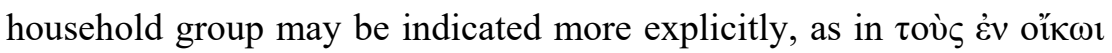
$\pi \alpha ́ v \tau \alpha \varsigma$ (four times: P. Wash. Univ. 2:106, 18 BC; P. Oxy 3356, AD

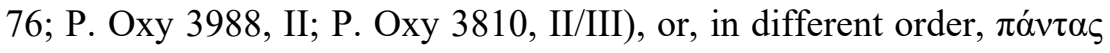

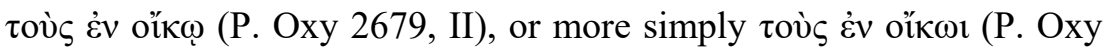
2787, II), or, among those sending greetings, oi غ่v oǐk $\pi$ óv $\tau \varepsilon \varsigma$ (P. Wash. Univ. 2:106, 18 BC; P. Oxy 3505, II?; P. Oxy 1761, ${ }^{33}$ II/III)

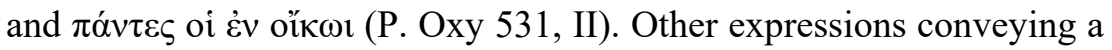

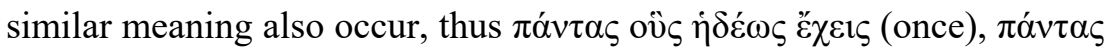

33 The cases and spelling are misconstrued, but this must be what the writer means to

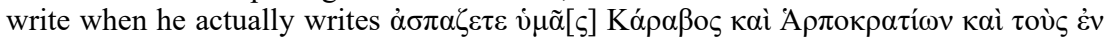

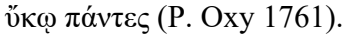




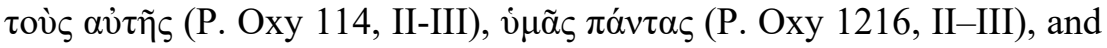

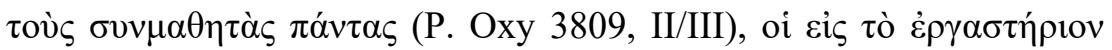
$\pi$ óv $\tau \varepsilon \varsigma$ (PSI 1332, II-III). ${ }^{34}$

Another interesting expression of this type is the request to greet a group of people, who are not named within the letter, 'by name', so we find the term $\kappa \alpha \tau$ ' övo $\mu \alpha$ added to a generalising expression in seven different letters. For example, in a letter dealing with various household instructions, and with no named greetings, $\ddot{\sigma} \sigma \pi \alpha \sigma \alpha \iota \tau[o v ̀ \zeta] \pi \alpha \rho ' \dot{\eta} \mu \tilde{\omega} v$

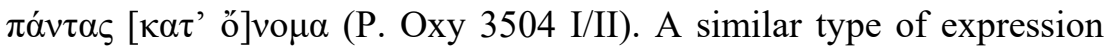
can also be used after a list of greetings for and from named people,

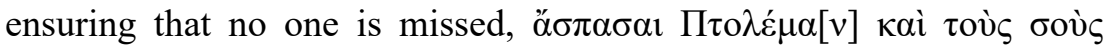

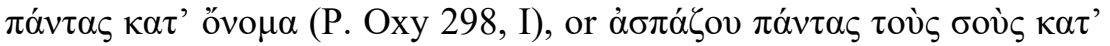

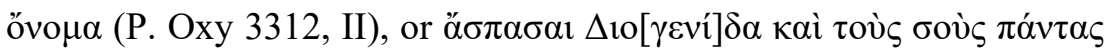

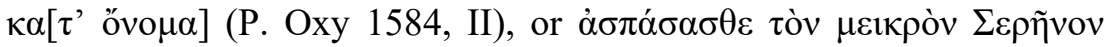

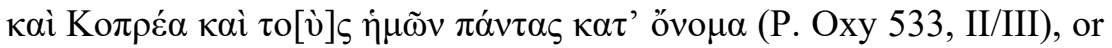

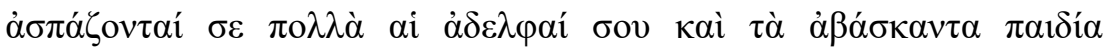

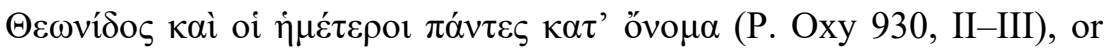

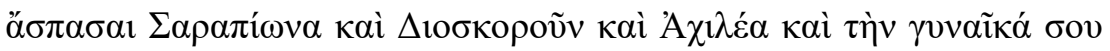

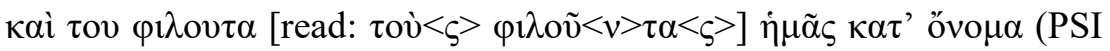
1332 , II-III). ${ }^{35}$

34 Paul uses a variety of similar expressions in his greetings, often, although not universally, adapts this type of expression with distinctively Christian identifiers, $\dot{\varepsilon} v$ кטpí

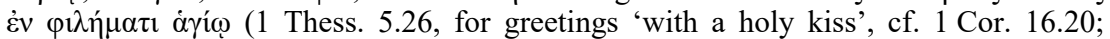

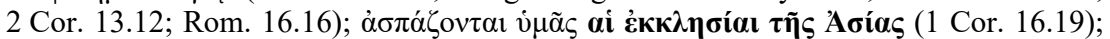

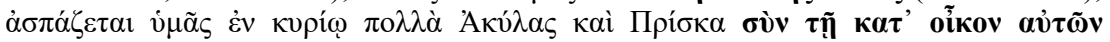

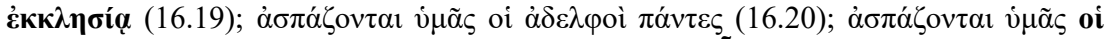

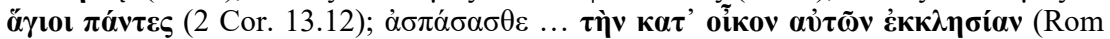

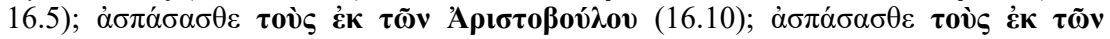

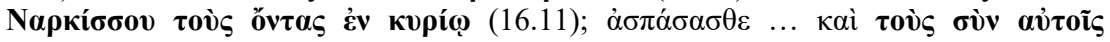

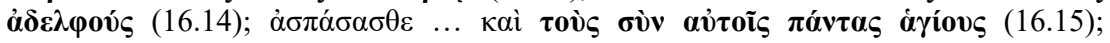

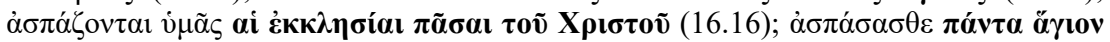

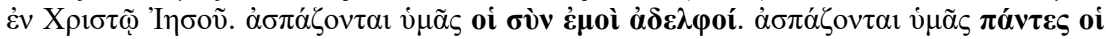

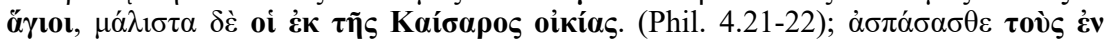

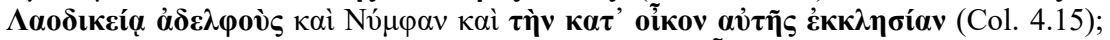

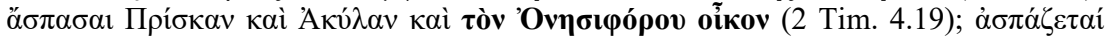

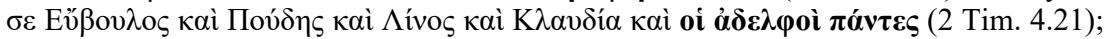

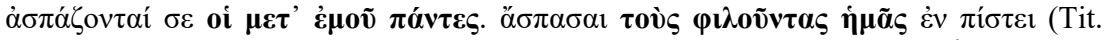

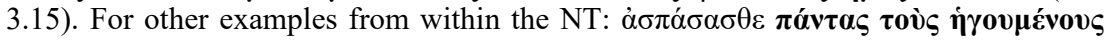

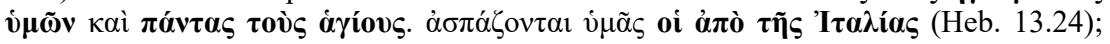

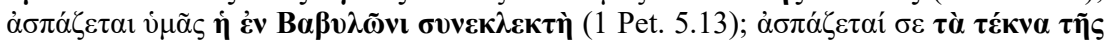

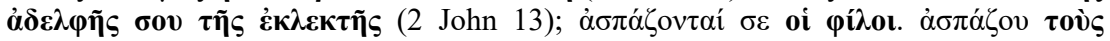

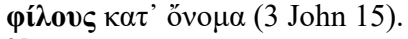

35 For similar greetings in early Christian letters cf. 3 John 15: $\alpha \sigma \pi \alpha \dot{\zeta}$ ov $\tau \alpha$ í $\sigma \varepsilon$ oi

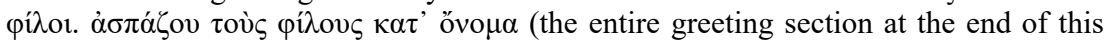




\section{Format issues in greetings}

In a discussion of a group of letters written by a single author in the early part of the second century, we noted two issues in relation to the structural formatting of the letters. Firstly, that there seemed to be a relationship between the size of the sheet of papyrus and the length and content of the greetings, and, secondly, that several of the letters contained a large blank space at the end of the letter body and before the beginning of the greetings, with an enlarged alpha at the beginning of $\alpha \sigma \pi \alpha \sigma \alpha l$ in the opening of the greetings. ${ }^{36}$

We have checked images for 56 of the 74 letters in our study and have found no significant observed correlation between sheet size and the extent of greetings. The letters come in a great variety of sizes and are generally filled with text. Three letters with a substantial amount of blank space already have substantial greetings (P. Oxy 2559, II; P. Oxy 3313, II; P. Oxy 2982) - the contents of these suggest a relatively wealthy context. ${ }^{37}$ In another three of the letters the main body of the letter takes up only around half of the page and the 'farewell' is followed by additional greetings (P. Oxy 5286, AD 82; P. Oxy 3062, I; P. Oxy 3199, II), but no attempt is made to fill all of the available space. In at least one letter the greetings have extended into the margins (P. Oxy 295, AD 35). ${ }^{38}$

In relation to spaces and enlarged alphas in relation to the beginning of greeting sections, we found this is not a general characteristic, although some similar features were found in certain letters. So a number of letters exhibit spaces before the greeting section, reflecting a type of punctuation (P. Oxy 4624, I; P. Oxy 3504, II [bis]; P. Oxy 2787, II; P. Oxy 3852, II; P. Oxy 3992, II; P. Oxy 533, II/III); others begin the verb of greeting with bold ink reflecting a re-inked pen (P. Oxy 5286, AD 82; P. Oxy 1583, II; P. Oxy 1758, II; P. Oxy 2680,

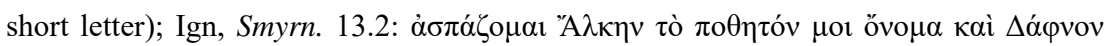

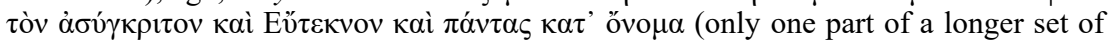
greetings closing this letter).

36 Head, 'The Letters of Claudius Terentianus and the New Testament', 236-37 (for these three points).

37 Another letter with a lot of blank space has only one brief greeting and the letter is introduced by the editors as 'An illiterate letter written in a rather large uncultivated hand' (P. Oxy 1215, II-III).

38 Cf. also probably P. Oxy 1154, late I (not included in this study because it lacks the key verb); P. Oxy 930, II/III (text extends into the margin, but not clear whether it is continuation of greeting). 
II); some letters do have the initial alpha written in at least a slightly larger or elongated manner (P. Oxy 295, AD 35 [?]; P. Oxy 5286, AD 82; P. Oxy 1583, II; P. Oxy 2981, II; P. Oxy 3312, II; P. Oxy 3313, II; P. Oxy 3990, II (?); P. Oslo II.52, II).

\section{Greetings either interrupted or followed by a reprise of major issue in letters}

Within these letters, the general convention for closing a letter is that the greetings are followed by a farewell wish (and sometimes a date). This form of closing occurs in around three quarters of the letters. ${ }^{39}$ There are some variations to this with some greetings coming after the farewell wish. ${ }^{40}$ An interesting variation to this convention is when an important topic, sometimes reprising a theme or issue from the body of the letter, is introduced between greetings and farewell wish. At the very least, this shows the willingness on the part of some writers to be flexible with epistolary conventions.

In one of our earliest examples only the lower portion of the papyrus survives, so we do not know the contents of the body of the letter (P. Oxy 2148, AD 27). The closing portion of the letter is as follows:

Greet Pausirion and Hermias and Heraclides and ... and your brothers' wives and children and all your friends. If you come across any mustard relish, buy it and make us some pickle. If you make anything good, make an extra amount for your brothers' house. And for the rest, farewell. The 13th year of Tiberius Caesar Augustus, Epeiph 12.41

A similar concern with pickle appears between the greetings and the farewell in a letter from Arsinoe to her sister Sarapias (P. Oxy 2680, II-III):

Greet Polykrates and all your people. Poleta and Demetrous greet you. If you want anything sent to you, write me and I will send it immediately

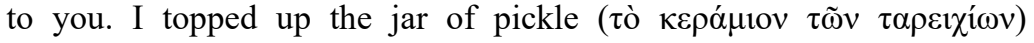

39 I have left the farewell portion of the letter in the following list.

40 Sometimes this involves an unusual structure, e.g. P. Oxy 5286 (AD 82): farewellgreeting-date; P. Oxy 114 (II-III): greeting-farewell-greeting; on other occasions it is used for greetings additional to those given before the farewell, e.g. P. Oxy 530 (II); 1584 (II).

41 Similarly, P. Oxy 3504 (I/II) consists of only the closing section of a private letter, where another matter is included within the context of the greetings and the farewell wish: 'Farewell, Greet all of our people by name and write to me about what you want. I shall do it with the greatest pleasure ...muthis greets you.' 
because it had sunk. The bottom layers are better than the top ones. Farewell. Choiak 27.

On this occasion, since the whole letter is extant, we know that this does reprise an issue from within the body of the letter ('Receive from

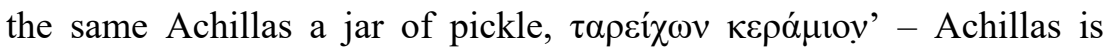
Arsinoe's brother and the carrier of the letter)..$^{42}$ The editor suggested that this portion of the letter 'may be in a different hand', so it is possible the author adds a more personal note to the body of the letter written by a secretary. ${ }^{43}$ More likely, in our view, is that the scribe realises that space on the papyrus sheet is limited and begins to write more compactly towards the end of the letter, with only the final farewell (and date) in the hand of the author.

P. Oxy 1155 is a brief letter (from Theonas to Apion, AD 104):

Theonas to his dearest Apion, many greetings. I wish you to know that as soon as I arrived at Alexandria I immediately attended to the matter about which you asked me. I found the man prospering in the main.

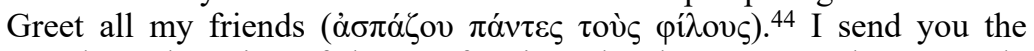
actual proclamation of the praefect in order that you may hasten to do what concerns you. Good-bye. The 7th year of the emperor Nerva Trajanus Augustus Germanicus Dacicus, Pachon 1.

Here it is not clear whether the matter raised between the greeting and the farewell wish - the proclamation of the prefect - is connected with the issue raised in the opening of the letter - 'the matter about which you asked me' concerning the man, or whether it is a second issue which Theonas has been asked to accomplish by Apion.

A connection between a comment interjected between greetings and farewell is clear in a letter from Dionysia to Panechotes (P. Wash. Univ. 2:106; 18 BC). ${ }^{45}$ The letter closes with typical greetings (although poor spelling):

Greet Athenis and Ptolla and Harasis and all those in the household. Ventidius greets you warmly and so do Helene and Outidion and all

42 There is no further indication of the contents of the pickle jar in P. Oxy 2680; it

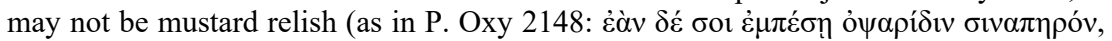

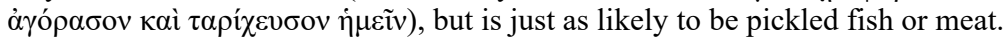

43 J. Rea, Oxy Pap 33 (1968), 117; cf. also R. S. Bagnall and R. Cribiore, Women's Letters from Ancient Egypt, 300 BC-AD 800 (Ann Arbor: University of Michigan Press, 2006): 300.

44 The lack of concord in case here (read $\pi \alpha v^{2} \tau \alpha \varsigma$ for $\left.\pi \alpha \alpha^{2} \tau \varepsilon \varsigma\right)$ is but one example of the 'very vulgar Greek' of which the editor speaks: A. S. Hunt, Oxy Pap 8 (1911): 257.

45 ET here from Bagnall and Cribiore, Women's Letters from Ancient Egypt, 300 BC$A D$ 800, 322 (photo on p. 323). 
those in the household. So don't be neglectful about the matter ( $\mu$ 门̀ oũv

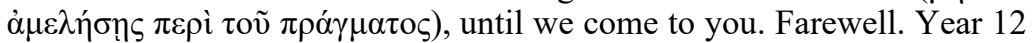
of Caesar, Tybi 18.

The 'matter' about which Dionysia is concerned is a request she made earlier in the letter:

I ask you to give testimony through the strategos to him, before Pedo sails up and I with my people sail down and present my case against

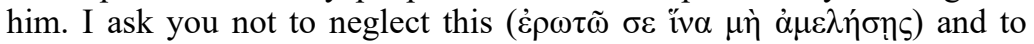
send me word as quickly as possible.

This additional comment after the greetings is really the main point of the letter.

P. Oxy 932 is a letter from Thais to Tigrius giving instructions concerning a range of business and agricultural issues. The letter

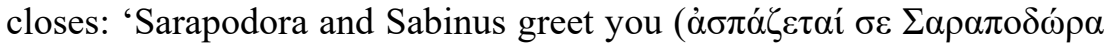
$\kappa(\alpha i) \Sigma \alpha \beta \tilde{i} v o \varsigma)$. Do not sell the young pigs without me. Good-bye.' This is not a reprise of a matter already raised, more likely a final point that the author remembered. ${ }^{46}$ Similarly, P. Oxy 2787 (II) is a brief letter with a message and greetings ('Greet the children and the people in the house. Chaeremon and the children greet you and Agathus greets

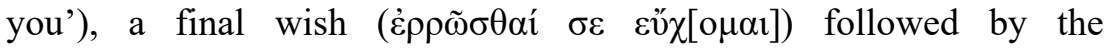
introduction of a new matter ('Since the strategus has given me orders about this matter, let Ariston read you the document that was sent to him'), before the repetition of the final wish to close the letter $\left(\dot{\varepsilon} \rho \rho^{\tilde{\omega}}[\sigma \theta \alpha i] \sigma \varepsilon \varepsilon \tilde{u} \chi[\circ \mu \alpha 1].\right)$

An excellent example of a letter writer adding a comment after the greetings to reinforce the message of the letter is in P. Oxy 4959, a letter from Ammonius to his parents (II). ${ }^{47}$ The letter is written to reassure his parents that his brother Theon had fully recovered from a severe illness. Ammonius refers to a letter from Theon to his parents on the same subject: he affirms that though they had been worried, Theon had recovered quickly, he swears on the gods that he is telling the truth,

46 Bagnall and Cribiore comment about the language and hand of the letter that 'The overall impression is of a skilled writer taking down exactly what is being said, rendering it faithfully but not attempting to redraft it.' Women's Letters from Ancient Egypt, 300 BC-AD 800, 297. P. Oxy 1584 (Theon writes to his sister, II) has

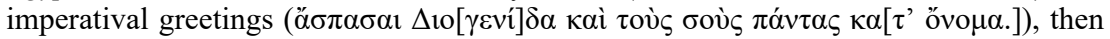
further matters of information (obscured because of its fragmentary state), then

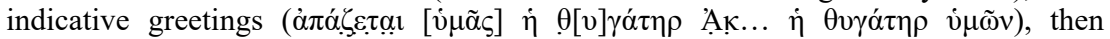
farewell, a date, and then another (imperatival) greeting ( $\alpha \sigma \pi \alpha \sigma \alpha \underline{1} \mathrm{~K} \varepsilon \varphi \alpha \lambda i \omega v \alpha)$.

47 P. Oxy 4959: the letter 'shows a very good command of Greek': M. Malouta, OxyPap 73 (2009): 155. 
and he contradicts any untrue reports they may have heard. Then he sends greetings followed by a final return to the main theme:

Your daughter and my brother Sotas send you their greetings. Give my best to Ptolemaeus and Antiochus, my brothers. I wish you good health, my most honoured (parents), and good fortune to the entire household ... I swear that my brother Theon is very well and doing his usual activities. $^{48}$

Another good example of this is P. Oxy 3313 (II). This substantial letter deals with a request from Dionysia for a large number of roses for the wedding of her son (we presume). The letter explains:

There are not many roses here yet; on the contrary they are in short supply, and from all the estates and from all the garland-weavers we could hardly get together the thousand that we sent you with Sarapas

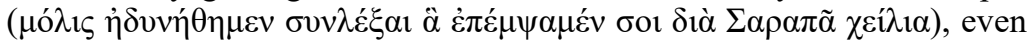
by picking the ones that ought to have been picked tomorrow.

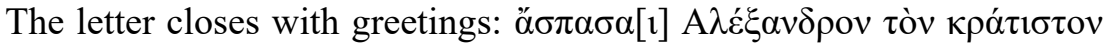

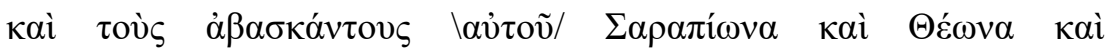

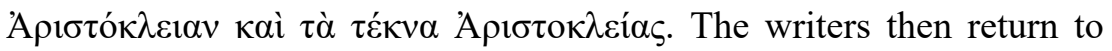
the roses: 'Sarapas will tell you about the roses - that I have made every effort to send you as many as you wanted, but we could not find them. ${ }^{49}$ The final health wish follows in a different hand (presumably

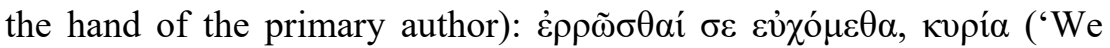
pray your health, lady').

On one occasion the greeting from a group of named individuals segues into a brief message from one of those named. In P. Oxy 2982 (II/III), a letter from one Theon to another Theon, which touches on a wide range of agricultural matters and instructions, concludes with

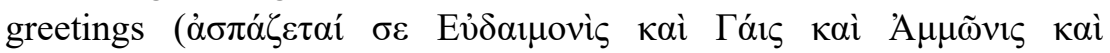

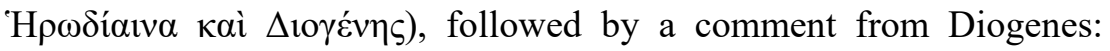
'Diogenes reproaches you with regard to the ratification of the twenty

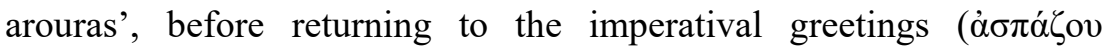

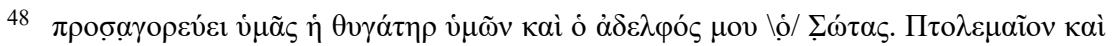

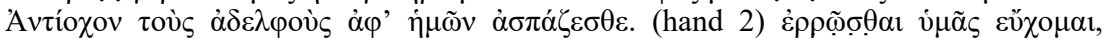

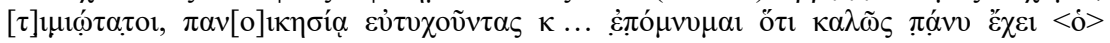

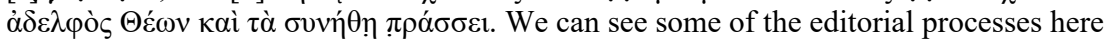
because a similar section was originally placed before the greeting [lines 15-17: $\delta \mathrm{\imath}$ '

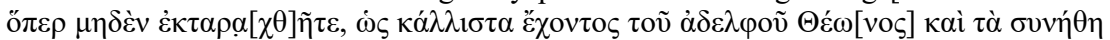

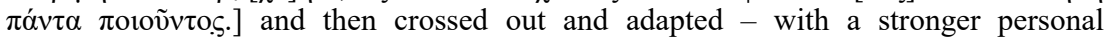
affirmation - for after the greeting.

49 On the importance of the letter carrier here see P. M. Head, 'Named Letter-Carriers among the Oxyrhynchus Papyri', JSNT 31 (2009): 279-99, esp. 293-94. 


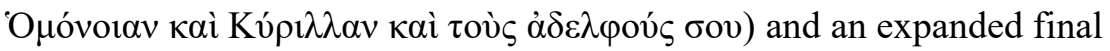

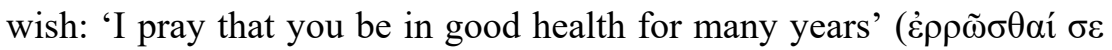

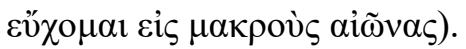

\section{Conclusion: the function of epistolary greetings}

Those letters which contain greetings (in either the imperatival or indicative form, or often, both) typically include greetings towards the close of the letter - after the main body of the letter and before the closing farewell. The only other common position for a particular greeting is right at the outset of the letter after the address. The examples we have surveyed show that greetings are part of the normal epistolary practice of Graeco-Roman antiquity, although letters obviously varied in the number and extent of greetings included. There was also considerable flexibility in the relationship between the greetings and the situation and main purpose of the letter, with greetings sometimes interrupted by the reprise and repetition of a key point within the letter. We might say that the sending of greetings, although not a universal feature of epistolary communication, is nevertheless a characteristic, even fundamental part of epistolary communication in antiquity.

Within the letters we have studied in this article greetings have the function of consolidating and maintaining connections between the writer and a more extended community than simply the recipient. Both individuals and groups of people can report their own greeting to the recipient (using the indicative form); the writer can request (using the imperative form) that his or her greetings can be passed to others in the circle of the recipient. The letter itself is normally written from one individual to another individual, but the greetings within the written letter serve to connect two communities, one around the sender and the other around the recipient. Among those specified we have seen that family relations have an important role in identifying those giving or receiving greetings.

We have dealt with some New Testament greetings only in the notes. Further study of the way in which NT writers expressed their greetings, in light of contemporary practice, is certainly warranted. In general, it is clear that the New Testament letter writers shared in the normal epistolary practice of their times, in terms of the syntax and 
content of their greetings, and the variety of the number and extent of greetings (adapted to express a particularly Christian view of both individual identity and of family and community relationships).

\title{
7. Appendix: Texts of epistolary greetings in Oxyrhynchyus Papyri
}

\author{
P. Oxy Date Text

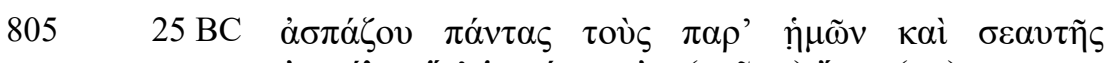

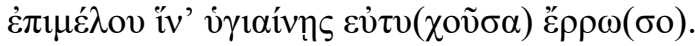

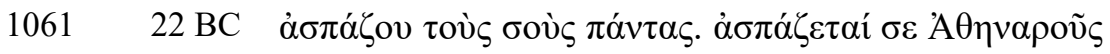

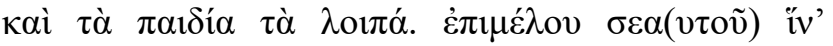

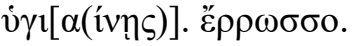

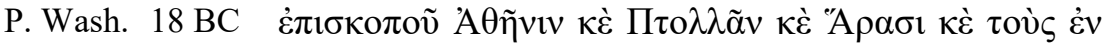

Univ.

2:106

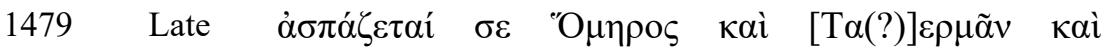

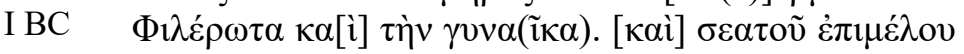

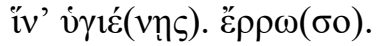

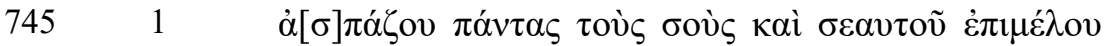

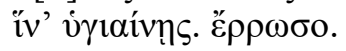

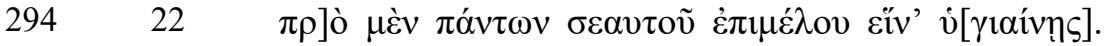

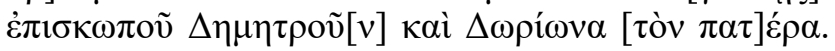
$\varepsilon[\rho] \rho \omega \sigma o$.

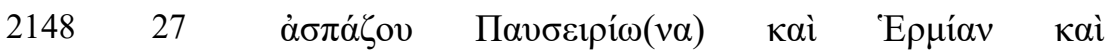

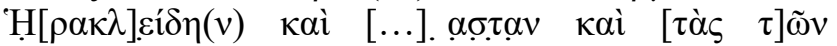

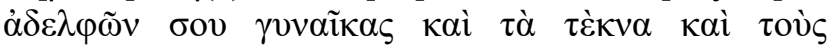

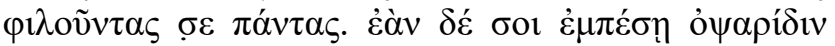

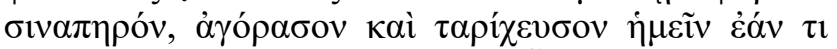

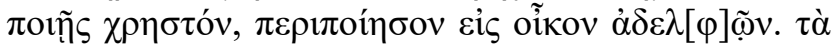
$\delta$ ' $\alpha$ $\lambda \lambda \alpha$ है $\rho \rho \omega \sigma(\mathrm{o})$.

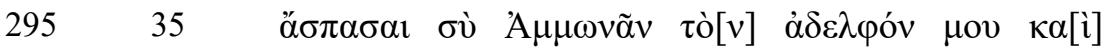

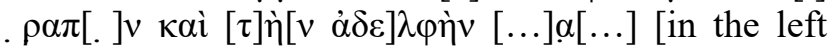

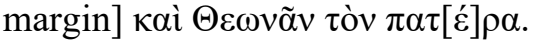

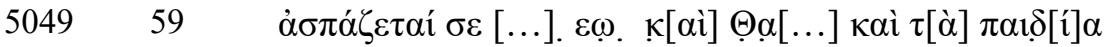


HEAD: Epistolary Greetings in the Oxyrhynchus Papyri

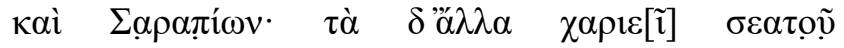
$\dot{\varepsilon} \pi \imath \mu \varepsilon \lambda o ́ \mu[\varepsilon] v o \zeta$. vac. 1 line है $\rho \rho \omega(\sigma o)$

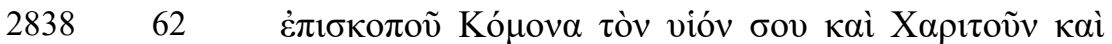

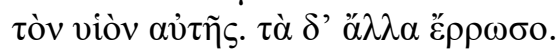

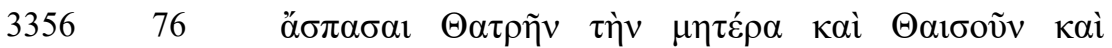

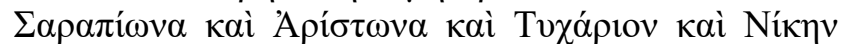

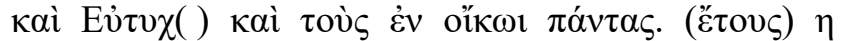

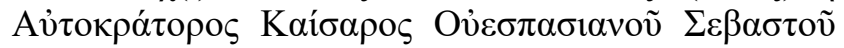

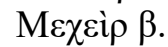

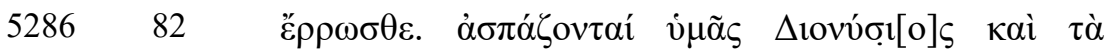

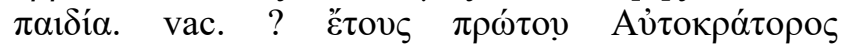

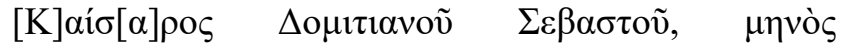
$[\mathrm{Kal}] \sigma \alpha \rho \varepsilon i ́ o v \kappa_{.}$.

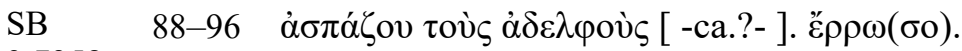

$3: 7258$

298

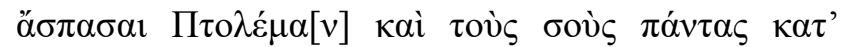

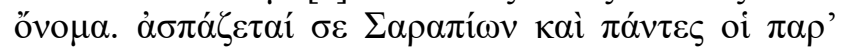

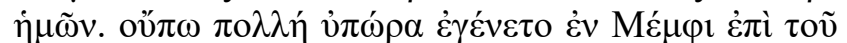

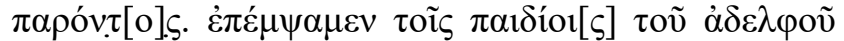

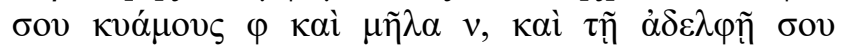

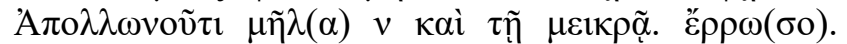

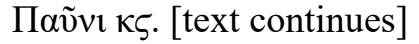

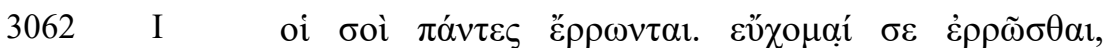

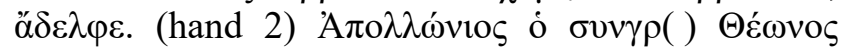

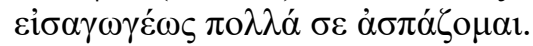

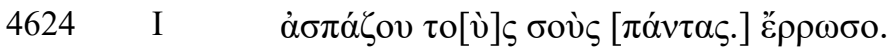

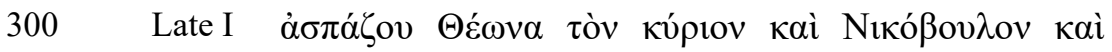

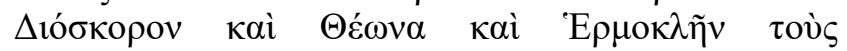

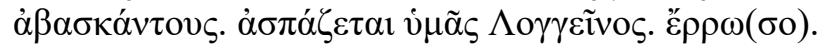

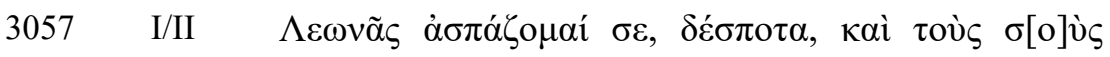

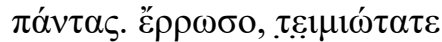

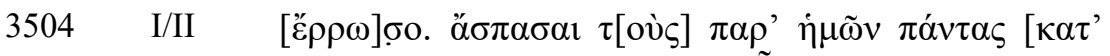

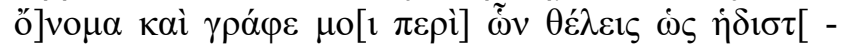

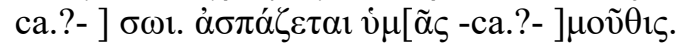

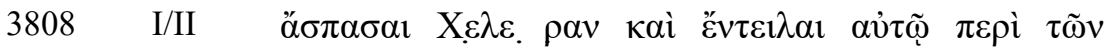

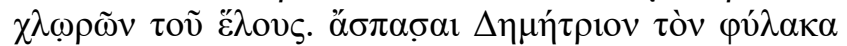

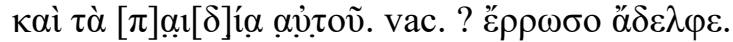

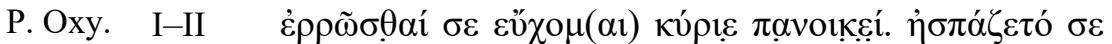
Hels 46

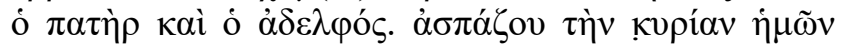

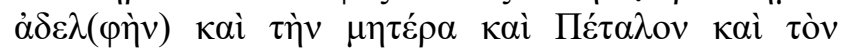


$\mathrm{A} \beta \alpha \imath \lambda()$

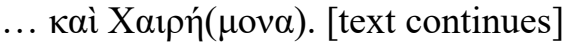

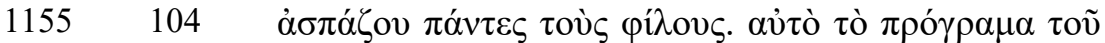

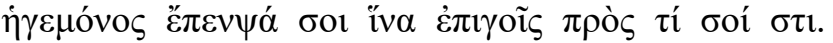
है $\rho \omega \sigma \sigma o$.

529 II

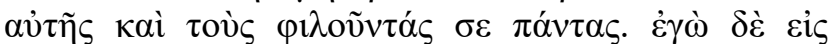

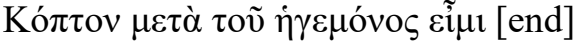

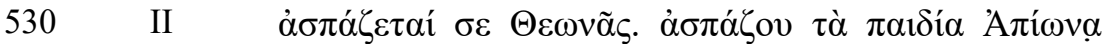

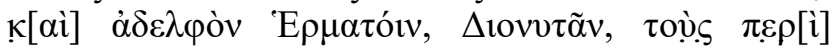

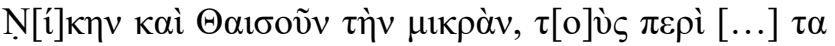

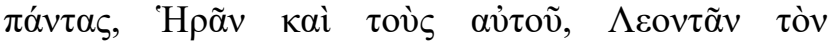

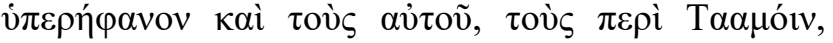

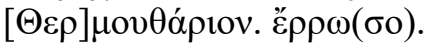

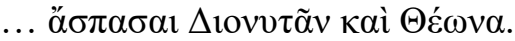

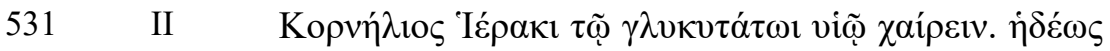

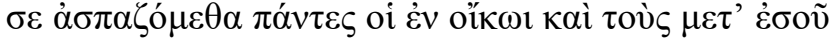
$\pi \alpha ́ v \tau \alpha \varsigma$. [after opening]

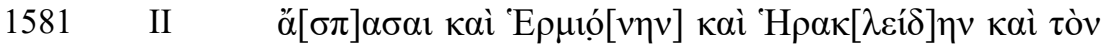

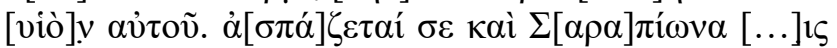

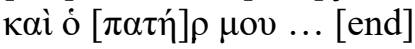

1582 II ḋ

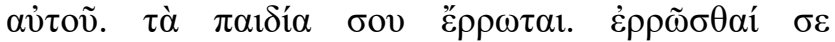
$\varepsilon \tilde{\chi} \chi 0(\mu \alpha), \ddot{\alpha} \delta \varepsilon \lambda(\varphi \varepsilon)$.

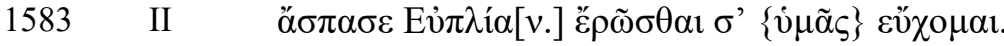

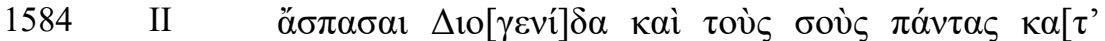

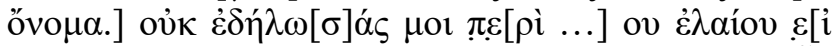

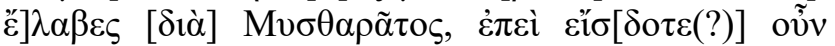

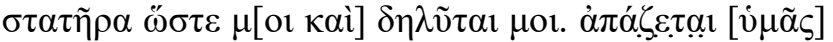

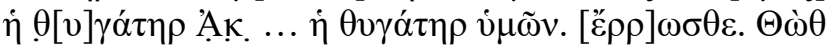

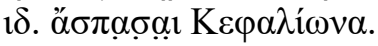

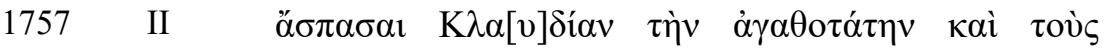

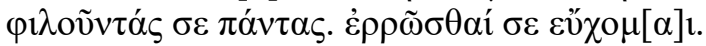

1758 II

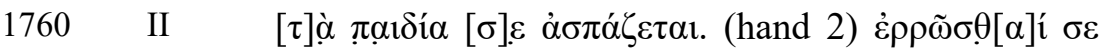
$\varepsilon v ้ \chi 0 \mu(\alpha)$.

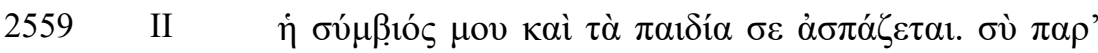

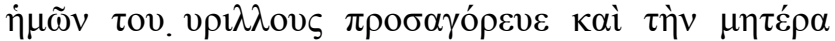

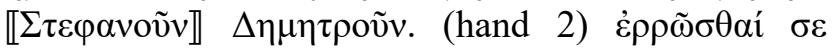

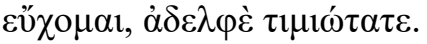

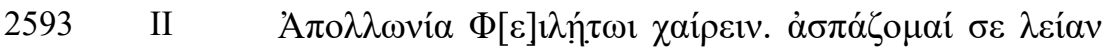


HEAD: Epistolary Greetings in the Oxyrhynchus Papyri

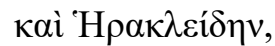

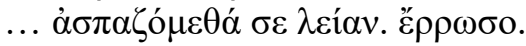

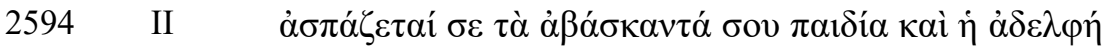

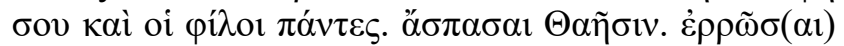

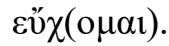

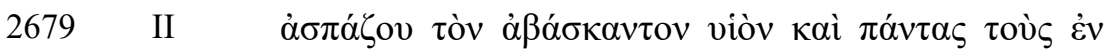

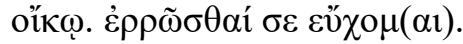

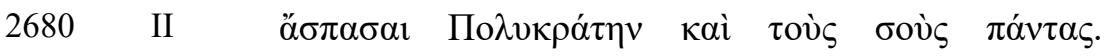

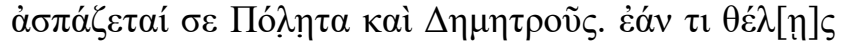

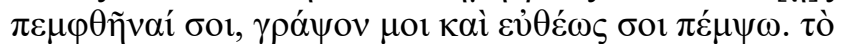

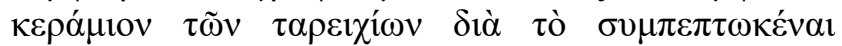

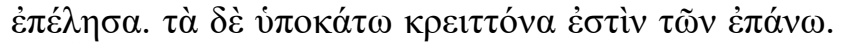
$\varepsilon \rho^{\tilde{\omega}} \rho^{\tilde{\omega}}(\sigma 0)$.

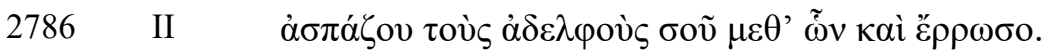

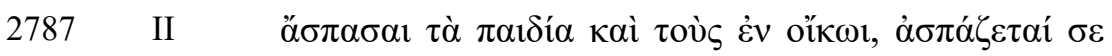

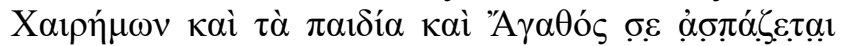
$\dot{\varepsilon} \rho \chi \circ \mu \varepsilon \dot{v} \omega \sigma \tau \ldots . . . .$.

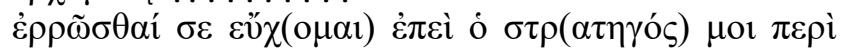

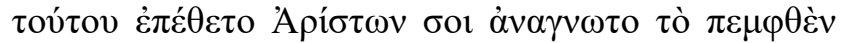

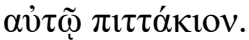

$\dot{\varepsilon} \rho \rho^{\tilde{\omega}}(\sigma \theta \alpha i) \sigma \varepsilon \varepsilon \hat{u} \chi(\mathrm{o} \mu \alpha \mathrm{l})$.

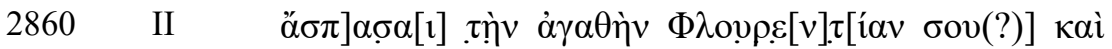

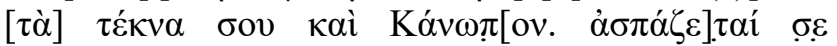

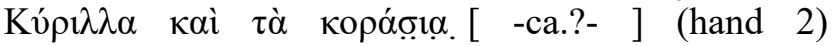

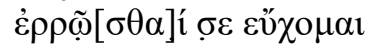

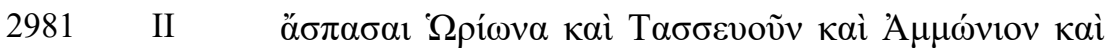

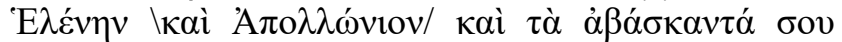

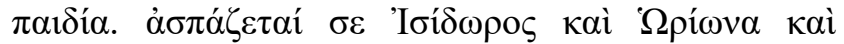

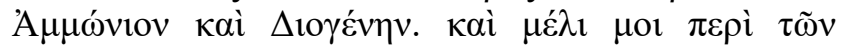

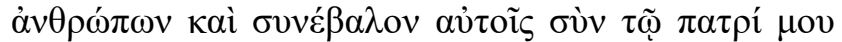

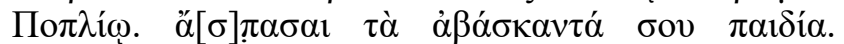

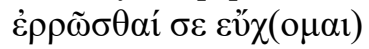

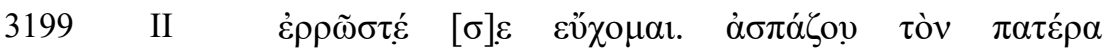
$\Sigma \alpha \pi \rho i ́ \omega v \alpha$.

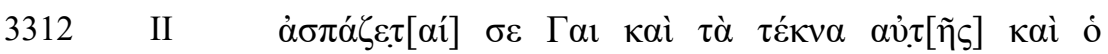

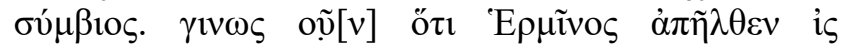

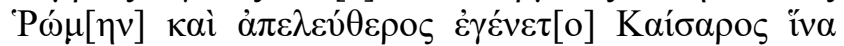

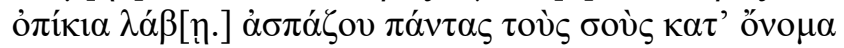

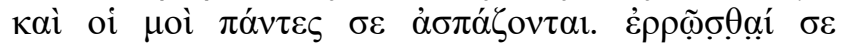

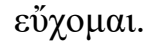

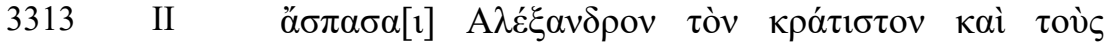




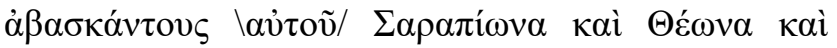

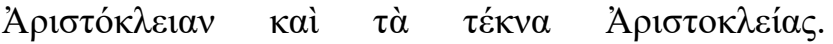

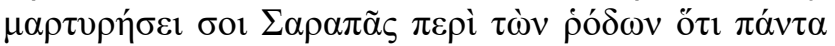

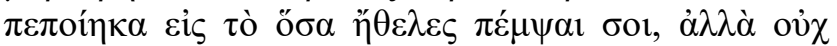

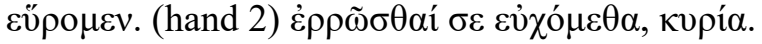

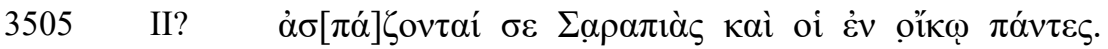

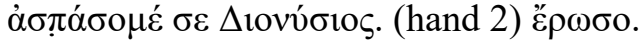

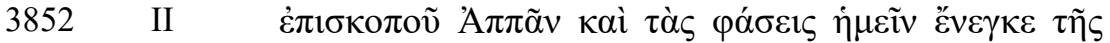

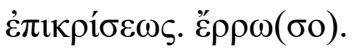

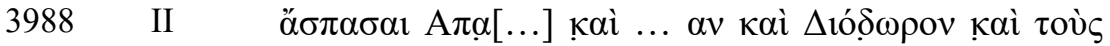

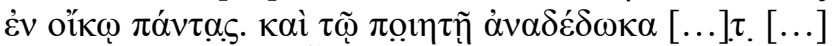

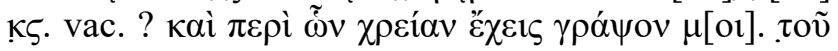

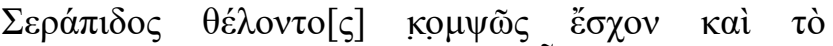

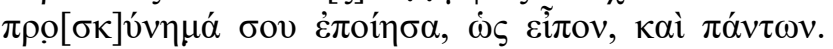
$\dot{\varepsilon} \rho \omega \sigma \varphi$

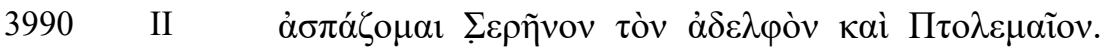

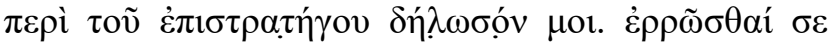
$\varepsilon \mho \mho \chi о \mu(\alpha), \dot{\alpha} \delta \varepsilon \lambda \varphi \eta ́$. [text continues]

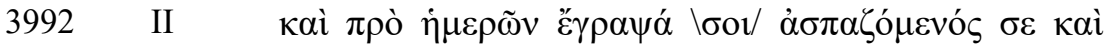

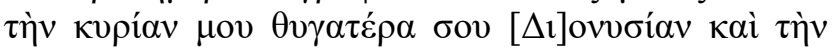

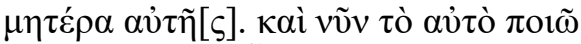

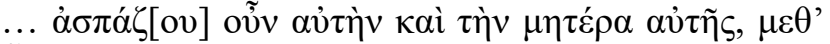

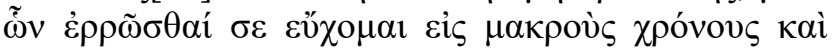

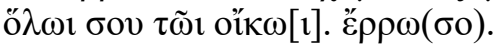

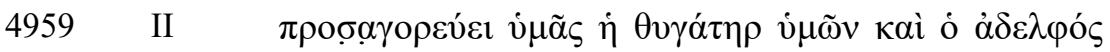

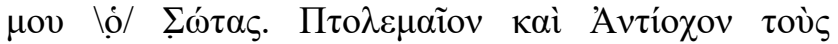

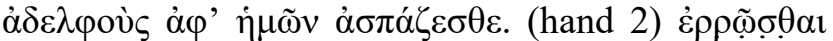

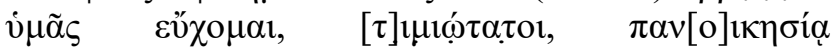

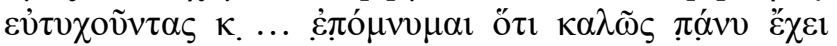

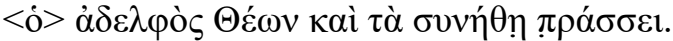

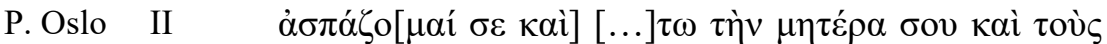

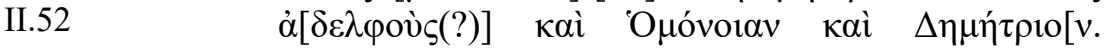

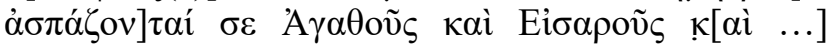

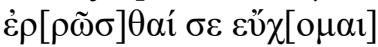

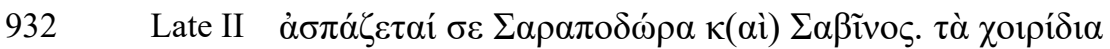

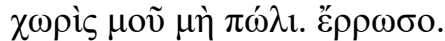

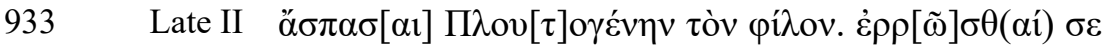

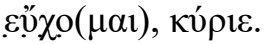

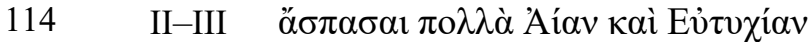

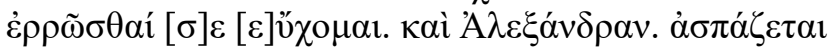

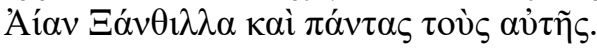


HEAD: Epistolary Greetings in the Oxyrhynchus Papyri

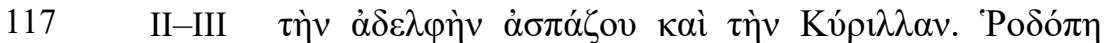

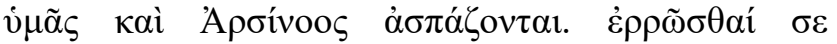

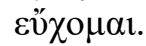

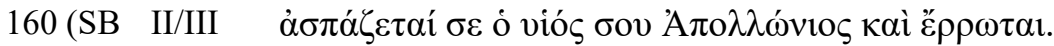

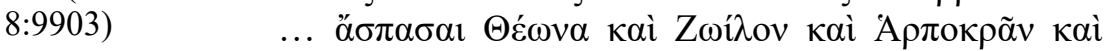

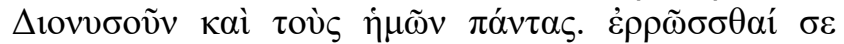

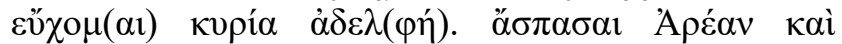

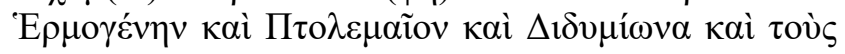
$\dot{\eta} \mu \tilde{\omega} \nu \pi \alpha ́ v \tau \alpha \varsigma$.

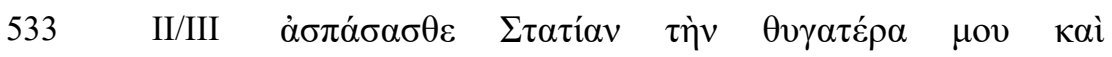

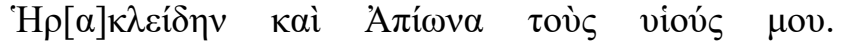

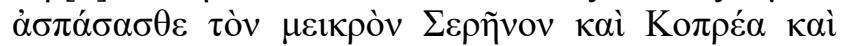

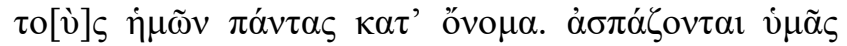

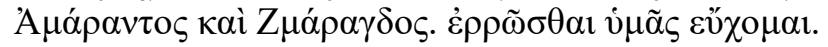

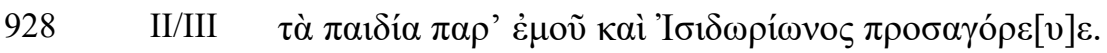

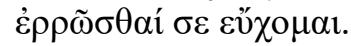

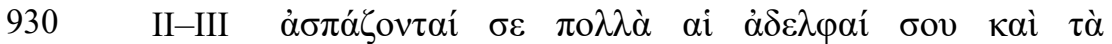

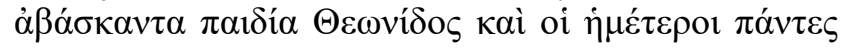

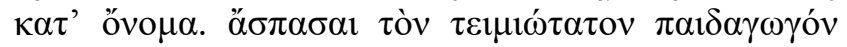
бov "Е $\omega \tau \alpha$. [in the left margin:] [ -ca.?- ] ... $\alpha 1 \delta \ldots$. $\dot{\varepsilon} \rho \rho[\ldots] \ldots[\ldots]$ A. $\theta \dot{\jmath} \rho \beta[$.

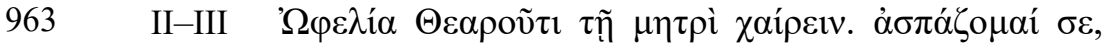

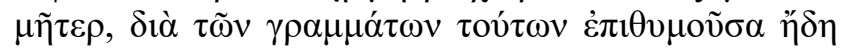
$\theta \varepsilon \alpha ́ \sigma \alpha \sigma \theta \alpha 1$.

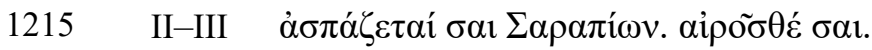

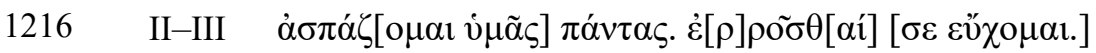

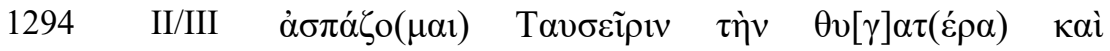
$\Sigma \alpha \rho \alpha \pi \tilde{\alpha} v$.

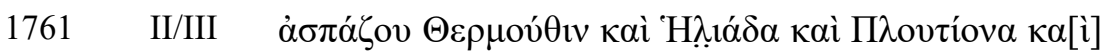

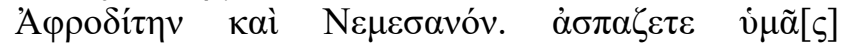

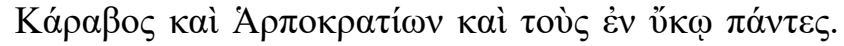

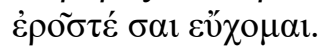

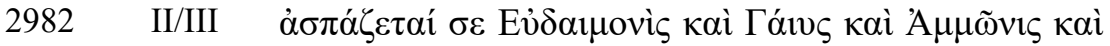

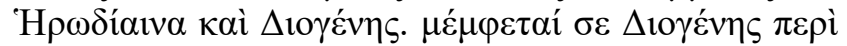

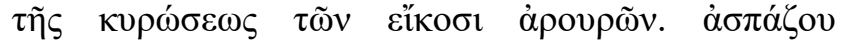

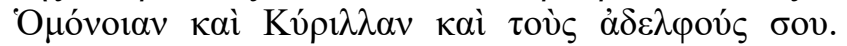

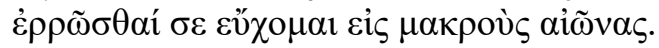

2984 II-III "А

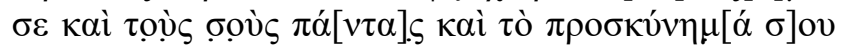

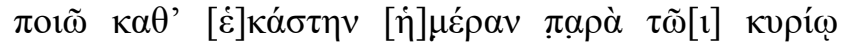
$\Sigma \alpha[\rho \alpha ́] \pi \imath \delta 1$. 


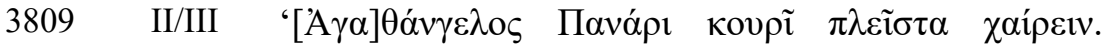
$[\dot{\alpha} \sigma \pi] \dot{\alpha} \zeta \omega \kappa \alpha \grave{~} \mathrm{H} \lambda \iota_{10 \delta} \omega \alpha \alpha$.

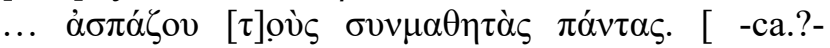
] ...[...]... [end]

$3810 \quad$ II/III $\quad \ddot{\alpha} \sigma \pi \alpha \sigma[\alpha 1]$ oò̀

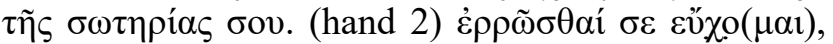

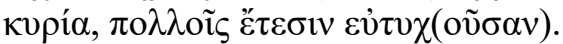

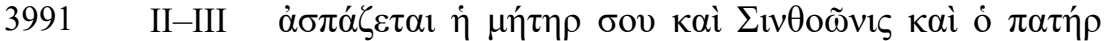

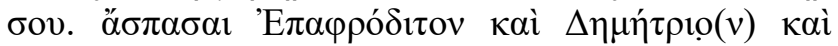

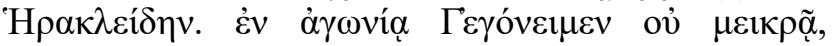

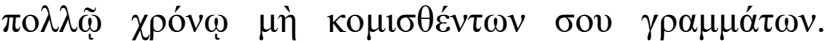
है $\rho \omega \sigma o . ~ Т \tilde{~} \beta 11 \zeta$.

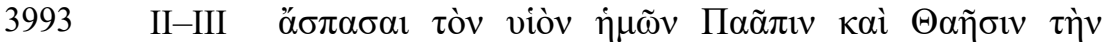

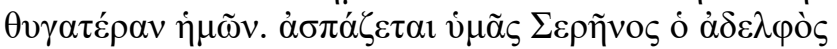

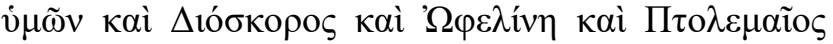

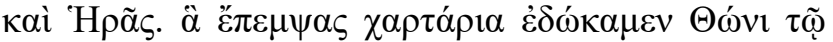

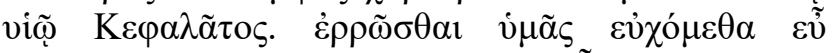

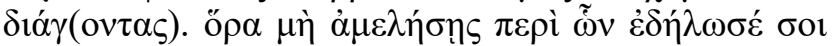
A $\pi \varphi \tilde{v} \varsigma$.

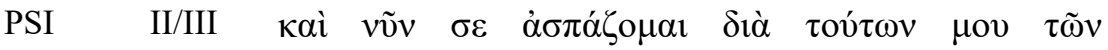
$1259 \quad \gamma \rho \alpha \mu \mu \alpha ́ \tau \omega v$.

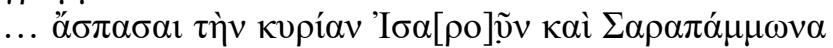

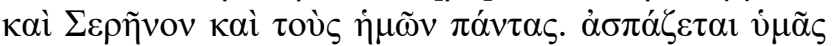

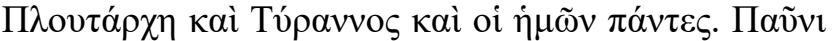

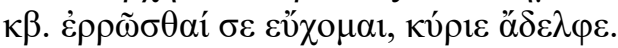

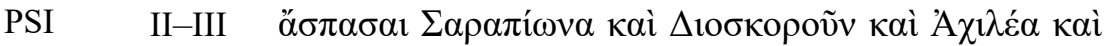

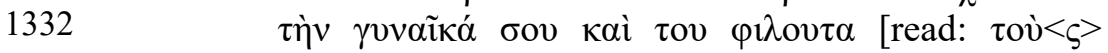

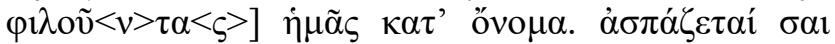

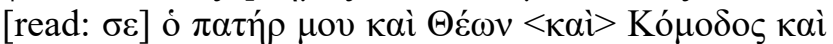

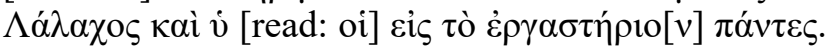

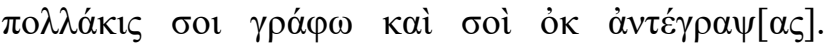

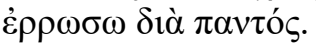

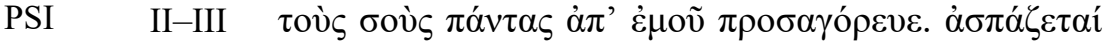

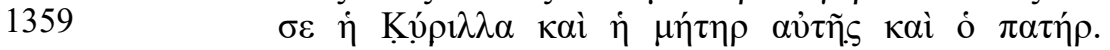

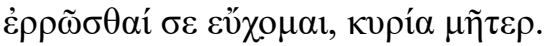

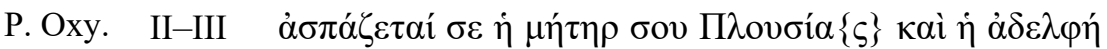

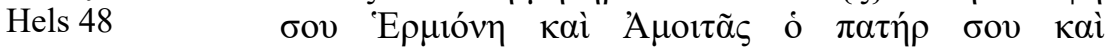

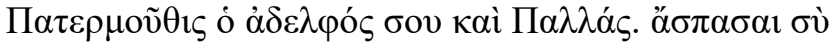

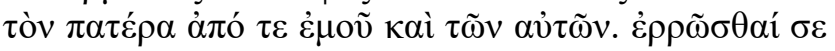

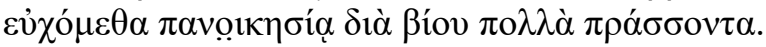

